\title{
Phyto-synthesis and structural characterization of catalytically active gold nanoparticles biosynthesized using Delonix regia leaf extract
}

\author{
Preeti Dauthal $^{1} \cdot$ Mausumi Mukhopadhyay $^{1}$
}

Received: 27 December 2015/Accepted: 21 May 2016/Published online: 2 June 2016

(c) The Author(s) 2016. This article is published with open access at Springerlink.com

\begin{abstract}
Biological methods of nanoparticles synthesis are ecologically sound and sustainable alternative to the conventional methods. On the basis of aforesaid premise, the present study deals with the optimization and fabrication of gold nanoparticles (Au-NPs) using easily available bio-resource, Delonix regia leaf extract. The use of practically nontoxic natural extracts and water allows the synthesis pathways presented to be considered as "green" and so permitting the synthesized Au-NPs to be used in sensitive areas, such as bioremediation. Various characterization techniques are adopted for the evaluation of size, stability, morphology, crystal nature, and purity of nanoparticles. Ultraviolet-visible spectroscopy analysis showed a surface Plasmon resonance peak for prepared AuNPs at $542 \mathrm{~nm}$, and its absorbance increased with increasing the interaction time. Transmission electron microscopy analysis showed that the particles were spherical and 4-24 nm in size. Energy dispersive X-ray spectroscopy analysis displayed a $2.2 \mathrm{keV}$ peak corresponding to the pure phase gold nanocrystal. X-ray diffraction analysis proved the fabrication of crystalline Au-NPs with face-centered cubic geometry within $10 \mathrm{~min}$. Furthermore, $\zeta$ potential $(-15 \mathrm{mV})$ and Fourier transform infrared data suggested the role of polar polyphenolic compounds of leaf extract in fabrication and stabilization process. Biofabricated nanoparticles are demonstrated to have catalytic activity for the reduction of toxic nitro-organic pollutant $o$-nitroaniline. Therefore, the present study
\end{abstract}

Mausumi Mukhopadhyay

mmu@ched.svnit.ac.in;

mausumi_mukhopadhyay@yahoo.com

1 Department of Chemical Engineering, S.V. National Institute of Technology, Surat 395007, Gujarat, India offers a straightforward, cost-efficient, eco-friendly, and sustainable alternative for the fabrication of catalytically active Au-NPs.

Keywords Delonix regia · Biofabrication · Gold · Nanoparticle $\cdot$ Nitroaniline

\section{Introduction}

Nanotechnology has significantly impacted every facet of human life ranging from pharmaceutical to cosmetics, clinical diagnostics to therapy, and pollution detection and their remediation. Every aspect of human life has been revolutionized with the advancements of nanotechnology in the area of metallic nanoparticles fabrication and their applications. Metallic nanoparticles exhibit a complete range of new and improved size- and shape-dependent physicochemical and biological properties that are significantly different from bulk counterparts (Singh et al. 2015). The material particles generally show fascinating and even unanticipated properties when they are in the nanorange of 1-100 nm. Noble metals, such as of gold, palladium, platinum, and silver with nano-size dimensions, have received considerable attention due to their endless promises in the field of material science (Dauthal and Mukhopadhyay 2013a). Among these noble metal nanoparticles (NPs), particularly gold nanoparticles (AuNPs) play a significant role in various catalytic reactions due to high-surface area-to-volume ratio, energetic surface atoms, and great surface energy (Bai et al. 2009). Traditionally, gold nano-catalysts are fabricated through various physical and chemical methods. Although existing methods have successfully produced well-defined NPs, the concerns regarding environmental pollutions and requirement of 
high-cost instrumental setups also increase simultaneously. The astringent reaction conditions due to the use of highly toxic and inflammable chemicals make these conventional processes unsuitable for various biological applications and restrict their scaling-up for industrial applications.

Biofabrication methods are not only a noble approach to synthesize benevolent nano structures, but also a footstep to diminish the utilization of toxic chemical and generation of perilous by-products which are hazardous to environment and public health (Jacob et al. 2012). These methods are considered as benign, sustainable, cost effective, and ecologically sound. Biofabrication of Au-NPs using microorganisms, such as bacteria (Alani et al. 2012; Srivastava and Mukhopadhyay 2014; Wang et al. 2015), fungi (Metuku et al. 2014), virus (Slocik et al. 2005), yeast (Agnihotri et al. 2009), and algae (Rajathi et al. 2012), are already reported. However, the use of the plant extract as the potential resource for the fabrication of NPs is gaining a significant importance, as unlike microbial fabrication, these methods do not involve isolation and culture preparation techniques (Gardea-Torresdey et al. 2003; Tripathy et al. 2010).

In a recent study, antioxidant potential of Delonix regia (D. regia) has been utilized for cost effective and ecobenign fabrication of palladium and gold-palladium NPs (Dauthal and Mukhopadhyay 2013b, 2016). Metal-reducing potential of one other plant species of Delonix genus is also reported recently for the synthesis of silver NPs (Sathiya and Akilandeswari 2014). However, literature survey revealed that there is no report available for the biofabrication of Au-NPs using D. regia. Thus, the present study is intended to fabricate Au-NPs utilizing the metalreducing potential of $D$. regia extract. To further strengthen this biofabrication approach, the effects of various process parameters, such as leaf extract concentration, temperature, time, and $\mathrm{pH}$ of the reaction, are also investigated for the fabrication of NPs. Furthermore, the catalytic potential of biofabricated NPs was evaluated for the reduction of anthropogenic pollutant $o$-nitroaniline (o-NA). The use of biofabricated NPs in this direction could be seen as a prominent alternative for traditionally synthesized polymer supported nanocatalyst (Zayed and Eisa 2014; Zayed et al. 2015), where the structure and functional group of polymer support influences the catalytic behavior of NPs (Liu et al. 2007). However, in the case of biofabricated NPs, surface biomolecules (functional groups) can act as a polymer support, and influence of external polymer support on catalytic activity of NPs can be minimized (Sharma et al. 2007; Gangula et al. 2011; Dauthal and Mukhopadhyay 2012, 2013b, 2015a, b). Furthermore, the inert behavior of supported biomass with an added advantage of ecofriendliness makes biofabricated NPs as noble tool for bioremediation.

\section{Experiments}

\section{Materials}

Tetrachloroauric (III) acid $\left(\mathrm{HAuCl}_{4} \cdot 3 \mathrm{H}_{2} \mathrm{O}, 99 \%\right)$, sodium borohydride $\left(\mathrm{NaBH}_{4}, \quad 98 \%\right)$, and $o$-Nitroaniline $\left(\mathrm{C}_{6} \mathrm{H}_{6} \mathrm{~N}_{2} \mathrm{O}_{2}, 98 \%\right)$ were procured from HiMedia Pvt. Ltd. Mumbai, India. Fresh leaves of D. regia were collected from the campus of S.V. National Institute of Technology Surat, Gujarat, India.

\section{Biofabrication of Au-NPs}

$30 \mathrm{~g}$ of fresh leaf of D. regia was mixed with $120 \mathrm{~mL}$ of deionized water and heated at $60{ }^{\circ} \mathrm{C}$ for $10 \mathrm{~min}$ and then filtered. This solution was decanted and stored at $4{ }^{\circ} \mathrm{C}$ for further use. About $100 \mathrm{~mL}$ of aqueous $D$. regia leaf extract was added to $800 \mathrm{~mL}$ of $1 \times 10^{-3} \mathrm{M} \mathrm{HAuCl}_{4} \cdot 3 \mathrm{H}_{2} \mathrm{O}$ solution. This solution was kept at room temperature in a sealed flask, for $10 \mathrm{~min}$. For control experiments, the same amount of D. regia leaf extract and $\mathrm{HAuCl}_{4} \cdot 3 \mathrm{H}_{2} \mathrm{O}$ solution was maintained separately at the same reaction environment. The reduced Au-NPs were sonicated for $10 \mathrm{~min}$ to separate Au-NPs from the bio-organics of D. regia leaf extract. Repeated centrifugation (14,000 rpm for $10 \mathrm{~min})$ was performed after sonication. After centrifugation, pellets were washed with deionized water and dried followed by characterization using different techniques.

\section{Catalytic reduction of $o$-NA}

In a glass vial, $3 \mathrm{~mL}$ of $o$-NA $\left(0.5 \times 10^{-3} \mathrm{M}\right)$ was mixed with $0.12 \mathrm{~mL}$ of $\mathrm{NaBH}_{4}(1.0 \mathrm{M})$ and $1 \times 10^{-3} \mathrm{~g}$ of nanocatalyst (Au-NPs) at $28 \pm 2{ }^{\circ} \mathrm{C}$. The catalytic reduction of $o$-NA was monitored using UV-visible spectrophotometer. Catalytic reduction of $o$-NA was carried out using different concentration levels of Au-NPs $\left(0.5-2 \times 10^{-3} \mathrm{~g}\right)$ and reaction temperature range $\left(10-50{ }^{\circ} \mathrm{C}\right)$. To better understand the catalytic activity of NPs, blank reaction was also carried out for the reduction of $o$-NA in the absence of Au-NPs. To judge the recyclability of catalyst, the Au-NPs were separated from the reaction mixture by centrifugation followed by washing and drying and then reused for five cycles using the abovementioned procedure.

\section{Characterization}

Optical absorbance of biofabricated Au-NPs was monitored in DR 5000, HACH, USA UV-visible spectrophotometer. $\zeta$ potential and hydrodynamic size distribution of NPs were determined using Zetasizer Nano ZS90, Malvern, 
UK instrument. CM200, Philips, UK; TEM was used for TEM imaging and selected area electron diffraction pattern (SAED) measurements. X'Pert Pro, PANalytical, Holland was used for the analysis of XRD spectrum of NPs. Elemental analysis was carried out using EDX detector (INCAX-sight, Oxford, UK) coupled with SEM (JSM6380LV, JEOL, Japan). FTIR analysis of Au-NPs was performed on FTIR, MAGNA 550, Nicolet, USA.

\section{Results and discussion}

\section{UV-visible analysis}

UV-visible spectra of biofabricated Au-NPs as a function of interaction time (5-1440 min) are represented in Fig. 1a. It was observed that the gold SPR peak observed at $542 \mathrm{~nm}$. Intensity of this SPR peak was gradually increased as a function of interaction time without any significant change in the SPR position. Fabrication of Au-NPs occurs fairly rapidly. No significant change detected in position and intensity of SPR even after $720 \mathrm{~min}$ of incubation. The
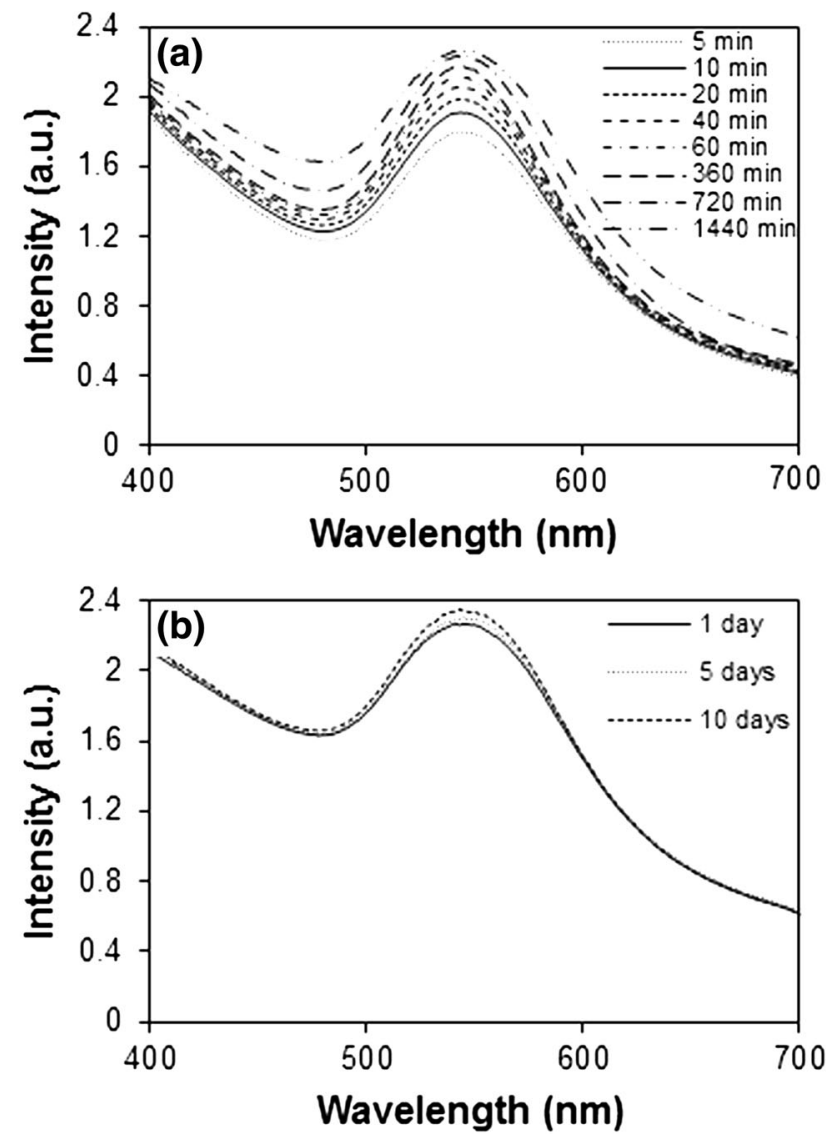

Fig. 1 UV-visible spectra of D. regia-mediated colloidal Au-NPs (a) interaction time 5-140 min (b) long-term interaction study (1-10 days) appropriate maximum absorbance was found to be 2.234-2.259 for 720-1440 min. This confirmed the complete reduction of $\mathrm{Au}^{3+}$ to $\mathrm{Au}-\mathrm{NPs}$ within $720 \mathrm{~min}(12 \mathrm{~h})$. Since more than $85 \%$ conversion of $\mathrm{Au}^{3+}$ to $\mathrm{Au}-\mathrm{NPs}$ was completed within first $10 \mathrm{~min}$ of the reaction time; therefore, $10 \mathrm{~min}$ of reaction time was considered for the synthesis of Au-NPs.

The long-term stability and aging effect on biofabricated Au-NPs was evaluated by monitoring its SPR position and $\zeta$ potential over a time period of 10 days. No significant change was observed in the SPR position and intensity (Fig. 1b), suggested the long-term stability of NPs.

The $\zeta$ potential was found to be $-14.3 \mathrm{mV}$ even after 10 days of incubation period, gave an additional proof of the long-term stability of Au-NPs. A negative value of $\zeta$ potential indicated the existence of repulsion force among particles and thereby increasing the stability. Thus, it may be concluded that there was not much agglomeration of the Au-NPs even after preserving solution for 10 days, validating the stability of NPs.

\section{DLS analysis}

DLS data represented the distribution of NPs in the range of $12-55 \mathrm{~nm}$ (average size $39 \mathrm{~nm}$ ) with polydispersity index 0.279 , which appears to be higher as compared to TEM (4-24 nm) and XRD measurements (25.77 nm) (Fig. 2a). This was due to interference created by
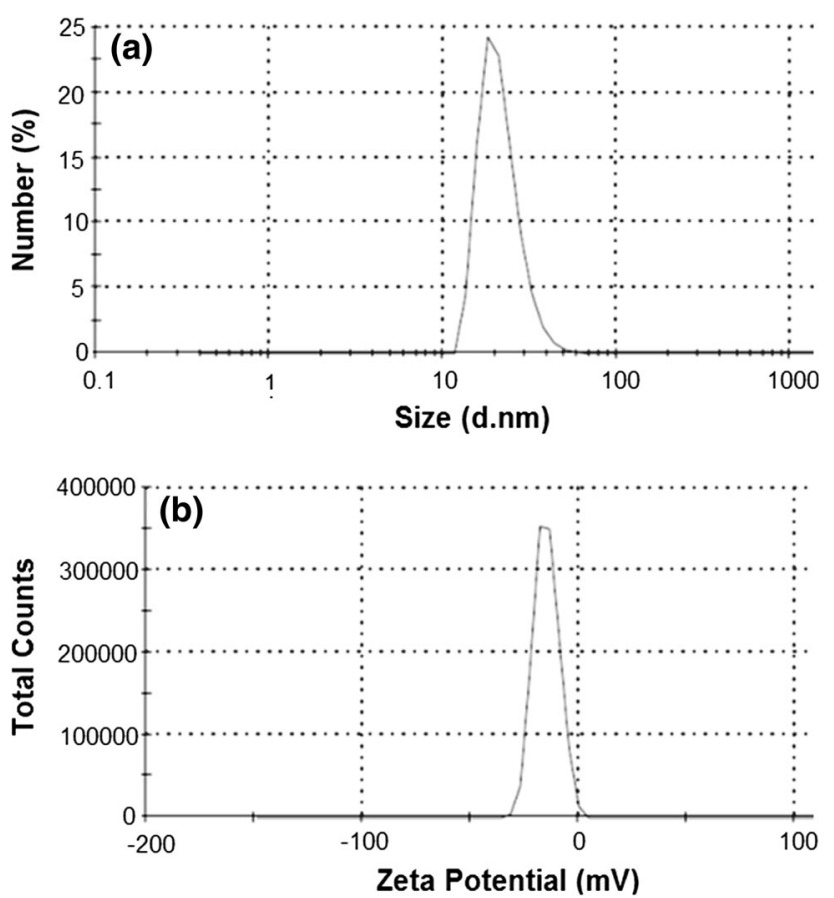

Fig. 2 Biofabricated Au-NPs (a) hydrodynamic size (b) $\zeta$ potential distribution 
electrical double layer on charged particles and overlapping NPs. However, the aggregation of NPs was avoided in the TEM imaging technique lead more precise observation (Suresh et al. 2011). In overall, the results of $\zeta$ potential value for Au-NPs obtained from colloidal solution were $-15 \mathrm{mV}$, suggested the stability of biofabricated NPs (Fig. 2b).

\section{TEM analysis}

TEM micrograph (Fig. 3a, b) clearly represented a welldispersed assembly of Au-NPs ranged in dimension between 4 and $24 \mathrm{~nm}$. Figure $3 \mathrm{c}$ showed the size distribution histogram of the nanoparticles. This histogram was prepared by manual analysis of 100 nanoparticles. Histogram indicated the average size $(\mu)$ of the prepared AuNPs with the standard deviation $(\sigma)(10.74 \pm 5.23 \mathrm{~nm})$. Histogram obtained from TEM micrograph of Au-NPs suggested that the majority of the particles $(68 \%)$ were resided in the size range of $5.51 \mathrm{~nm}(-1 \sigma)$ and $15.97 \mathrm{~nm}$ $(+1 \sigma)$. Au-NPs predominately adopted a spherical morphology. No other shapes were observed, suggested the role of oxidized polyphenols of $D$. regia as stabilizing and capping agent for freshly fabricated Au-NPs, which avoided further growth. This observation was also supported by the FTIR and $\zeta$ potential analysis. It was also visible that the edges of the NPs were lighter than center, suggested capping and adherence of bio-organics of leaf extract on the surface of NPs (Ahmad et al. 2010). The crystalline structure of the Au-NPs was also detected by SAED pattern (inset in Fig. 3b). Well-defined spotty rings in SAED pattern represented the (111), (200), (220) and (311) reflections of crystalline Au-NPs.

\section{XRD analysis}

The phase of the biofabricated Au-NPs was investigated by the XRD analysis and corresponding XRD pattern represented in Fig. 4. Figure represented clear Bragg's reflections of face-centered cubic (fcc) phase of Au-NPs present at $38.46^{\circ}(111), 44.43^{\circ}(200), 65.01^{\circ}(220), 77.81^{\circ}$ (311), and $82.25^{\circ}$ (222) positions (JCPDS No. 04-0784). The Bragg peaks of the Au-NPs are considerably broadened due to the small size of the nano-crystallites. The relative intensity of the (200)-(111) Bragg's reflections was higher than the conventional value (0.45) suggested (111) face-enriched Au-NPs. Lattice constant calculated from this pattern was $4.069 \AA$ established fcc geometry of NPs. Average particles size was calculated to be $25.77 \mathrm{~nm}$ using the line width of dominating (111) Bragg's peak. Thus, the XRD spectrum demonstrates strong evidence in favor of TEM imaging for the presence of Au-NPs.
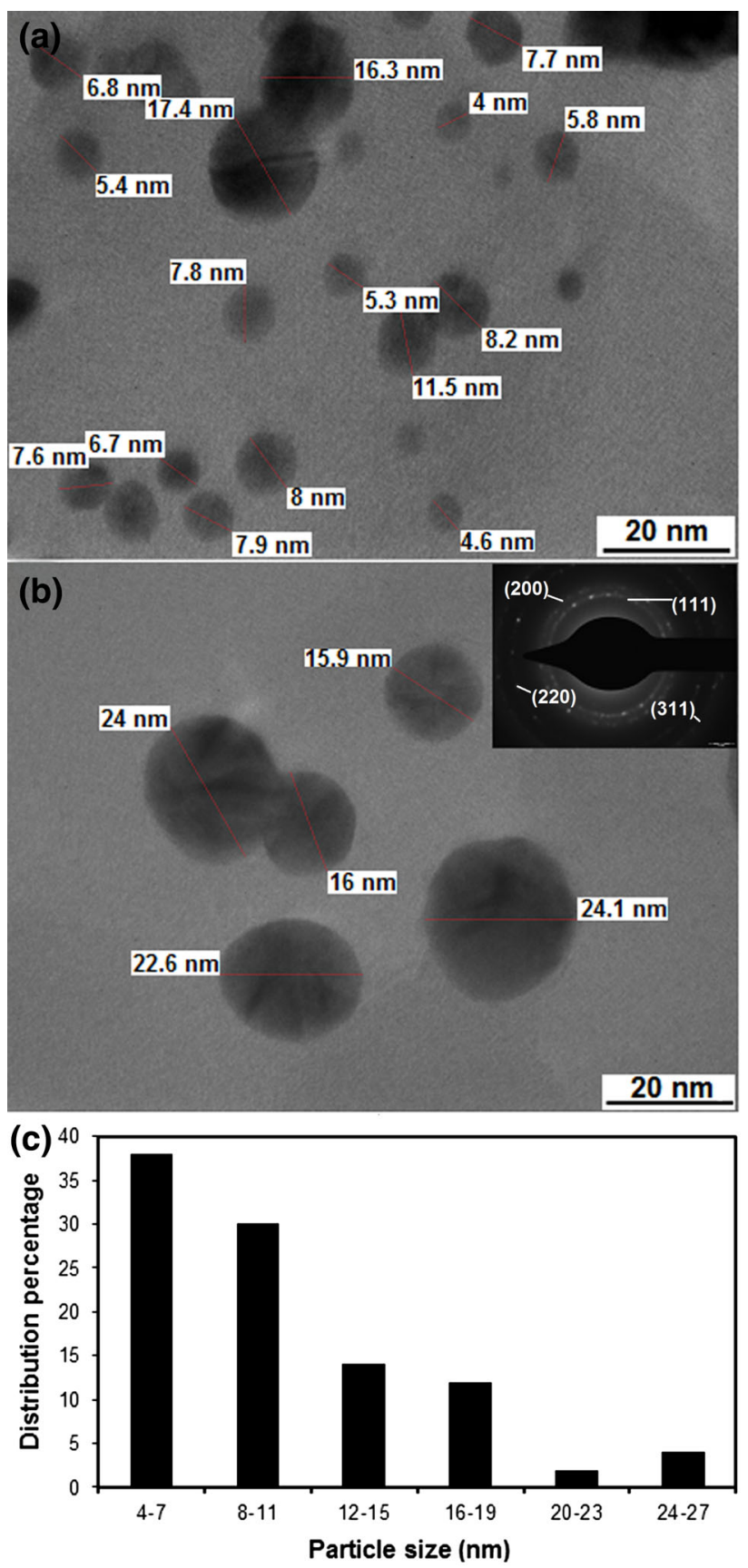

Fig. 3 Surface morphology and size analysis of Au-NPs (a-b) TEM (scale bar $20 \mathrm{~nm}$ ) (c) size distribution histogram (SAED pattern at inset)

\section{EDX analysis}

EDX analysis was performed to confirm the fabrication of Au-NPs using D. regia leaf extract. EDX plot was acquired by plotting kilo electron volt $(\mathrm{keV})$ against count per second/electron volt (cps/eV) (Fig. 5). An intense signal observed at $2.2 \mathrm{keV}$ due to SPR indicated the presence of Au. Elemental signals of $\mathrm{C}$ and $\mathrm{O}$ were also recorded possibly due to the involvement of carbonyl group of 


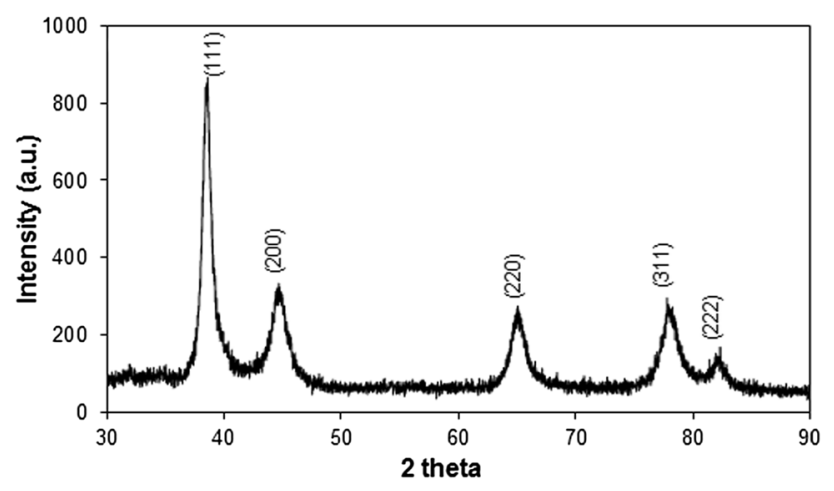

Fig. 4 Principal Bragg reflections of biofabricated Au-NPs

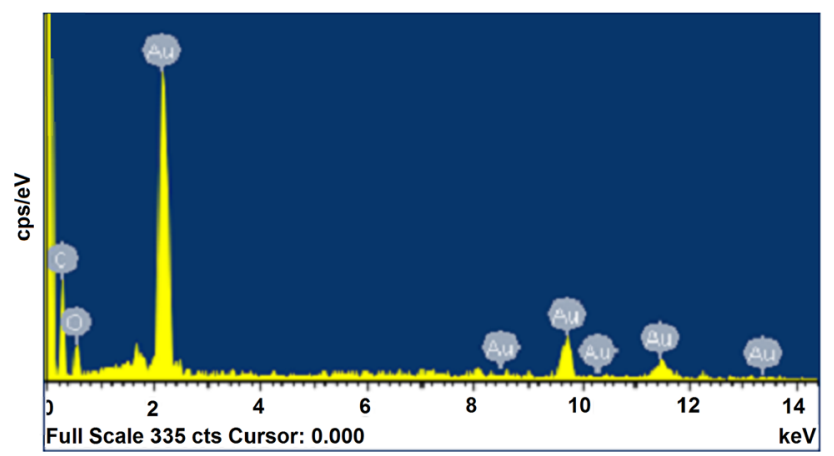

Fig. 5 EDX spectrum of biofabricated Au-NPs

oxidized polyphenols residues in capping and stabilizing of Au-NPs (Hudlikar et al. 2012).

\section{FTIR analysis}

To foresee the involvement of bio-functional groups of leaf extract of D. regia in biofabrication of NPs, the FTIR analysis was performed for Au-NPs (Fig. 6). Complex nature of $D$. regia leaf extract (not treated with salt solution) was confirmed from FTIR spectrum of leaf extract, as reported earlier in the literature (Dauthal and Mukhopadhyay 2013b) (Fig. 6a). The FTIR spectra of D. regia leaf extract showed absorption bands at 3471, 2925, 1710, $1640,1456,1378$, and $1230 \mathrm{~cm}^{-1}$ represented $\mathrm{O}-\mathrm{H}, \mathrm{C}-\mathrm{H}$, $\mathrm{C}=\mathrm{O}, \mathrm{C}=\mathrm{C}, \mathrm{O}-\mathrm{H}, \mathrm{C}=\mathrm{O}$, and $\mathrm{C}-\mathrm{OH}$ stretching vibration of polyols. These bands indicated that polyols (phenolic acid and flavonoids) are abundant in D. regia leaf, as reported earlier (Dauthal and Mukhopadhyay 2013b).

Minor changes were observed in positions and the magnitude of the stretching vibration in the FTIR spectrum of D. regia leaf extract after the bioreduction of $\mathrm{HAuCl}_{4-}$ $3 \mathrm{H}_{2} \mathrm{O}$ (Fig. 6b). Significant narrowing observed in the region of $2800-3600 \mathrm{~cm}^{-1}$ indicated that the $\mathrm{O}-\mathrm{H}$ group of polyols participated in the bioreduction reactions. Furthermore, a new stretching vibration was also observed at $1553 \mathrm{~cm}^{-1}$ (representing $\mathrm{C}=\mathrm{C}$ stretching in the aromatic

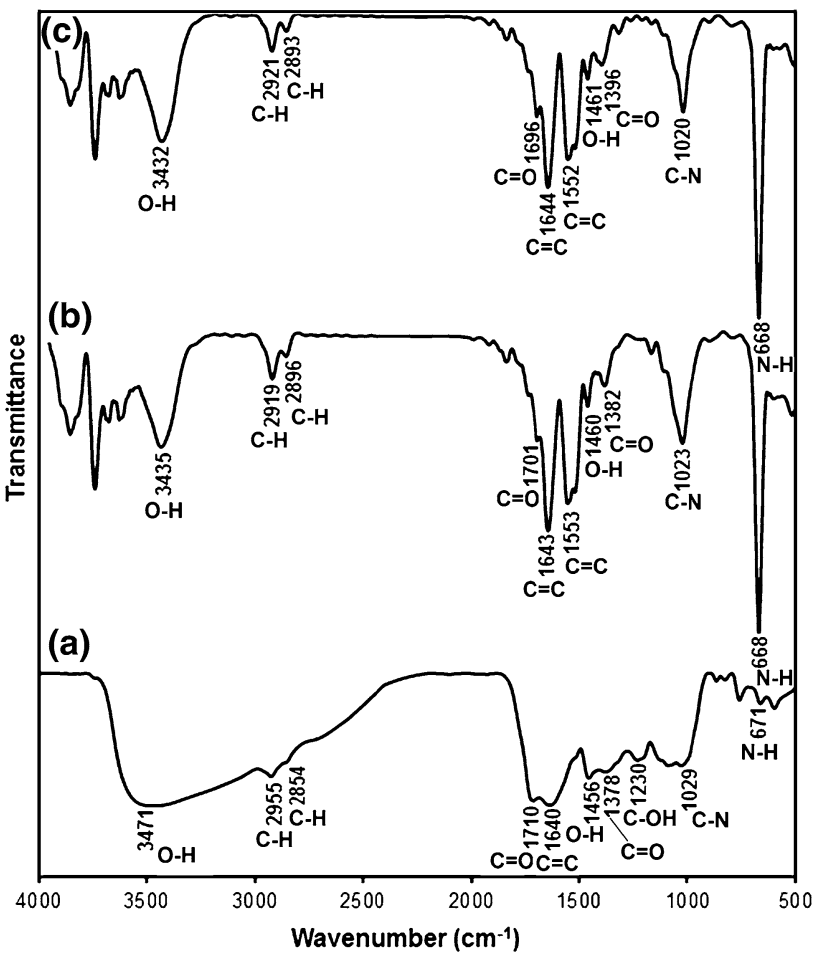

Fig. 6 FTIR spectra of (a) D. regia leaf extract before bioreduction (b) D. regia leaf extract after bioreduction (c) biofabricated Au-NPs

ring). The peaks of 1640,1456 , and $1029 \mathrm{~cm}^{-1}$ were shifted to new positions 1643, 1460, and $1023 \mathrm{~cm}^{-1}$, respectively, in FTIR spectra of D. regia after bioreduction. Changes observed in the FTIR spectrum of D. regia leaf extract after bioreduction indicated the participation of polyols having functional groups of $\mathrm{O}-\mathrm{H}, \mathrm{C}-\mathrm{H}, \mathrm{C}=\mathrm{O}, \mathrm{C}=\mathrm{C}$, $\mathrm{O}-\mathrm{H}, \mathrm{C}=\mathrm{O}$, and $\mathrm{C}-\mathrm{OH}$ in bioreduction reactions.

Several peak present at 3432, 2921, 2896, 1696, 1644, 1552, 1461, 1396, 1020, and $668 \mathrm{~cm}^{-1}$ positions in FTIR spectrum of Au-NPs also reflected the involvement of different functional groups of phytochemicals of $D$. regia in biofabrication process. The presence of water soluble polyphenolic compounds, including protocatechuic acid, gallic acid and hydroxybenzoic acid (phenolic acid), and catechin (flavonoids), is reported earlier in leaf extract of D. regia by the HPLC analysis (Dauthal and Mukhopadhyay 2013b). Metal-reducing potential of these water soluble heterocyclic compounds was also reported earlier (Yoosaf et al. 2007). Functional groups associated with these polyphenolic compounds may thus be involved in reducing the $\mathrm{Au}^{3+}$ and stabilizing nanostructures.

In general, polyphenols present in natural products have at least two hydroxyl groups at para or ortho positions to each other and are reported to have good metal-reducing activity (Yoosaf et al. 2007). All the reported polar polyphenolic compounds of leaf extract possess two hydroxyl groups each. Therefore, all reported polyphenolic 
compounds may involve in the reduction of $\mathrm{Au}^{3+}$ ions and converted into their respective quinones. Oxidized polyphenol (quinones) may act as ligands which facilitates the coordination of carbonyl groups with the freshly fabricated Au-NPs and substantially enhanced their stability (Fig. 7). Similar type of interaction was also demonstrated earlier between carbonyl oxygen atom of Polyvinylpyrrolidone and NPs surface (Zhou et al. 2009).

\section{Catalytic reduction of $o$-NA}

Real-time monitoring of catalytic reduction of $o$-NA was done by UV-visible spectroscopy, where characteristic absorbance peak of $o$-NA present at 410 and $283 \mathrm{~nm}$ exhibited a progressive decrease, along with slight shift in absorption peak of 283 to $289 \mathrm{~nm}$ (Fig. 8a). This reduction reaction of $o$-NA followed three steps, adsorption of $o$-NA onto the surface of catalyst (Au-NPs), interfacial electron transfer, and desorption of the $o$-NA on the surface. Thus, Au-NPs as a catalyst facilitate the reduction reaction of $o$ NA by reducing its activation energy $\left(E_{\mathrm{a}}\right)$. A control experiment was carried out devoid of Au-NPs under the same experimental condition. There was no significant change observed in the characteristic $o$-NA peak at $410 \mathrm{~nm}$ and did not give any signature of the formation of 1 , 2-benzenediamine. However, in the presence of Au-NPs, reduction of $o$-NA followed pseudo-first order, where linear correlation observed between $\ln \left(o-\mathrm{NA}_{0} / o-\mathrm{NA}_{t}\right)$ and reaction time $(t)$, where $o-\mathrm{NA}_{0}$ and $o-\mathrm{NA}_{t}$ : absorbance of $o$ $\mathrm{NA}$ at the initial time (0) specific time interval $(t)$ (Fig. 8b). The pseudo-first-order rate constant $\left(k_{\text {app }}\right)$ was calculated from the slope to be $12.28 \times 10^{-2} \mathrm{~min}^{-1}$.

To study the effect of concentration of catalyst on rate of reduction, the concentration of Au-NPs was varied from 0.5 to $2 \times 10^{-3} \mathrm{~g}$, keeping all other parameters constant. Time-dependent reduction of $o$-NA was studied spectrophotometrically by the gradual decrease in the peak intensity at $410 \mathrm{~nm}$. A plot of rate constant $\left(k_{\text {app }}\right)$ versus concentration of biofabricated Au-NPs is shown in Fig. 9a. At lowest concentration of Au-NPs $\left(0.5 \times 10^{-3} \mathrm{~g}\right)$, the reduction rate of $o$-NA was calculated to be $3.19 \times 10^{-2}$ $\mathrm{min}^{-1}$. Reduction rate was increased simultaneously with catalyst concentration, as catalytic reaction usually takes place at the surface of catalyst (Murugadoss and Chattopadhyay 2008). Therefore, the availability of more interaction site at high concentration of NPs ultimately increased the reduction rate.

The effect of temperature in reduction rate of $o$-NA was evaluated in the range of $10-50{ }^{\circ} \mathrm{C}$ (Table 1). At $10{ }^{\circ} \mathrm{C}$, $k_{\text {app }}$ of reduction reaction was found to be $3.52 \times 10^{-2}$ $\mathrm{min}^{-1}$, and it was increased to $35.38 \times 10^{-2} \mathrm{~min}^{-1}$ at $50{ }^{\circ} \mathrm{C}$. The temperature coefficient $\left(Q_{10}\right)$ for this catalytic
Fig. 7 Probable reaction of (a) bioreduction and (b) stabilization of $\mathrm{Au}^{0}$ using representative polyphenol (catechin)

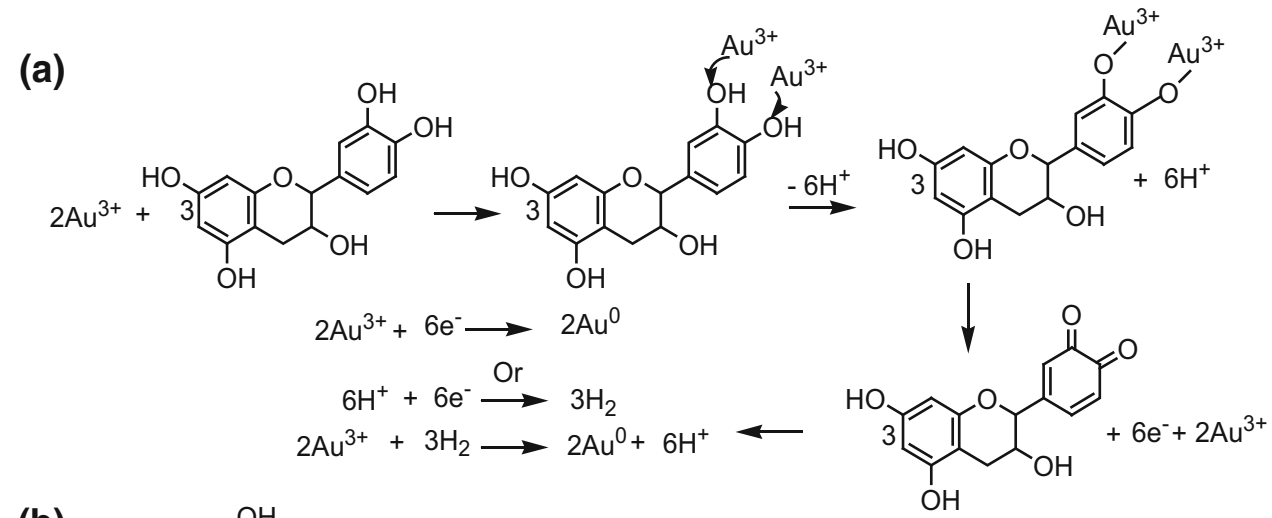

(b)

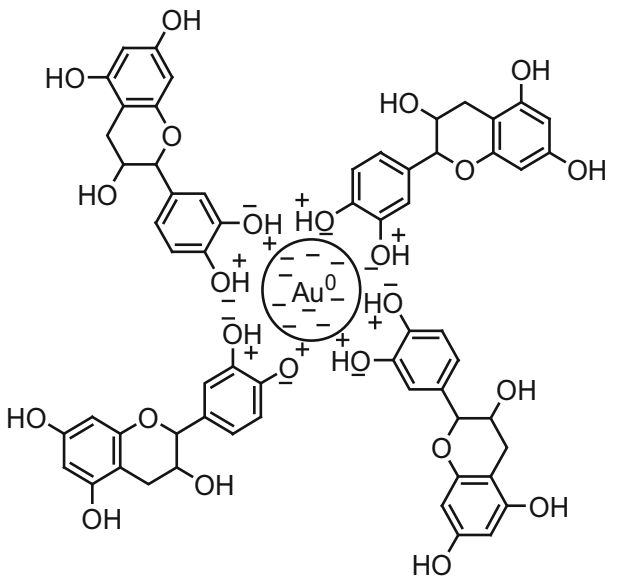



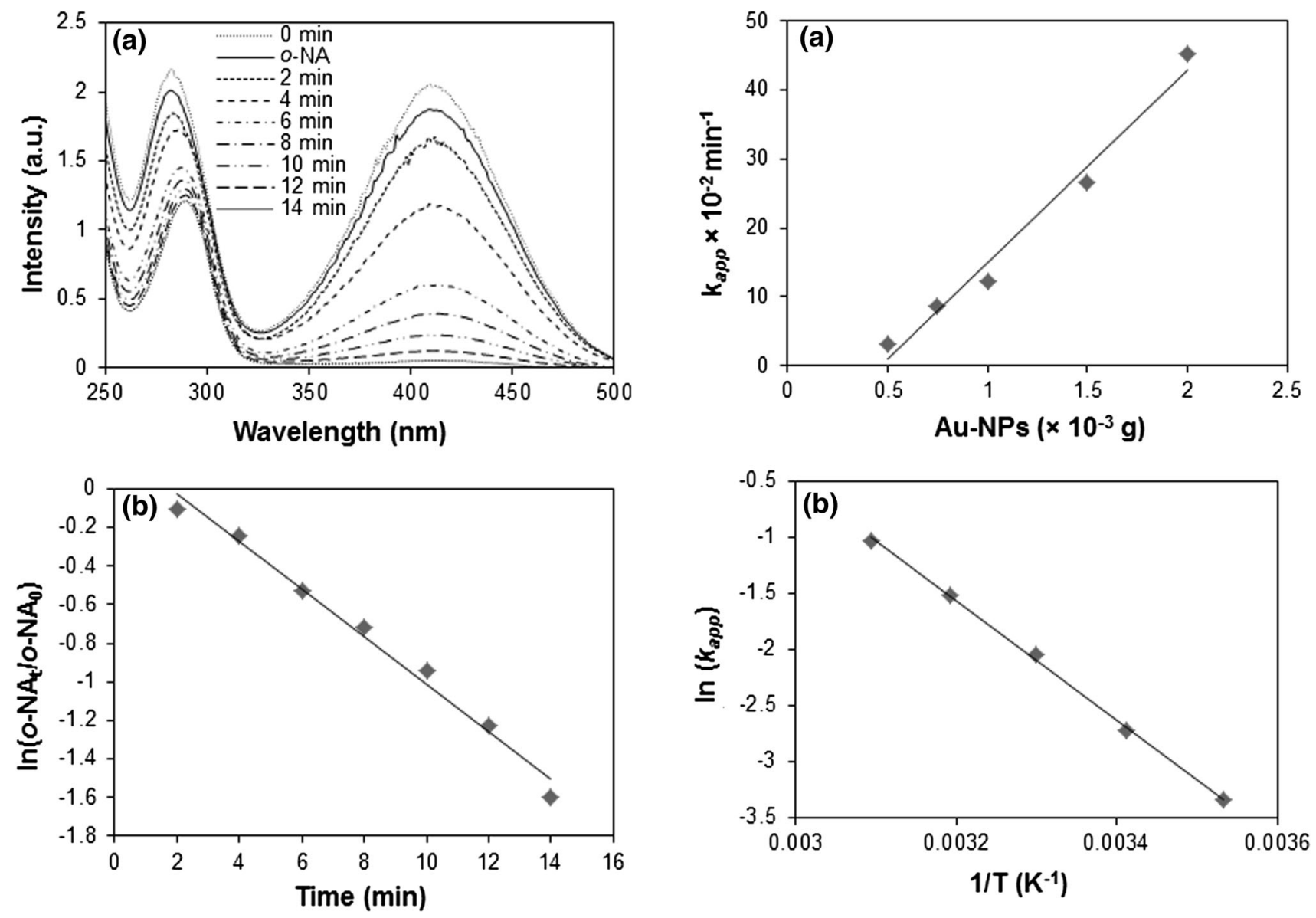

Fig. 8 a Absorption spectra of catalytic reduction of $o$-NA by $\mathrm{NaBH}_{4}$ using biofabricated Au-NPs as catalyst. b Pseudo-first-order kinetic plot of $\operatorname{In}\left(o-\mathrm{NA}_{\mathrm{t}} / o-\mathrm{NA}_{0}\right)$ against reaction time $t$ (reaction conditions $o$-NA $=0.5 \times 10^{-3} \mathrm{M} ; \mathrm{NaBH}_{4}=1 \mathrm{M} ;$ Au-NPs $=1 \times 10^{-3} \mathrm{~g}$; temperature $28 \pm 2{ }^{\circ} \mathrm{C}$ )

reduction was found to increase by the factor of 1.6-1.9 for each $10{ }^{\circ} \mathrm{C}$ rise in temperature using Eq. 1. Figure $9 \mathrm{~b}$ represented the Arrhenius plots of $k_{\text {app }}$ obtained in the range of $10-50{ }^{\circ} \mathrm{C}$. From the slope, the apparent $\mathrm{E}_{a}$ was calculated to be $44.26 \mathrm{~kJ} \mathrm{~mol}^{-1}$.

$Q_{10}=\left(\frac{k_{\text {app } 2}}{k_{\text {app } 1}}\right)^{10 /\left(T_{2}-T_{1}\right)}$

where $k_{\mathrm{app} 2}$ was the apparent rate constant at temperature $T_{2}$ and $k_{\text {app } 1}$ was the apparent rate constant at temperature $T_{1}, T_{1}$ and $T_{2}$ were the reaction temperatures, and $Q_{10}$ represented the factor by which $k_{\text {app }}$ of a reaction increases for every $10^{\circ}$ rise in the temperature.

\section{Catalytic recyclability of biofabricated Au-NPs}

After completion of one cycle of reduction reaction, the used Au-NPs were separated by centrifugation, followed by thorough washing with distilled water and drying.

Fig. 9 a Plot of $k_{\text {app }}$ against concentration of NPs (reaction conditions: $o$-NA $=0.5 \times 10^{-3} \quad \mathrm{M} ; \quad \mathrm{NaBH}_{4}=1 \mathrm{M} ; \quad \mathrm{Au}-$ NPs $=0.5-2 \times 10^{-3} \mathrm{~g}$; temperature: $28 \pm 2{ }^{\circ} \mathrm{C}$ ). b Arrhenius plot for the reduction of $o$-NA over Au-NPs catalyst (reaction conditions $o$-NA $=0.5 \times 10^{-3} \mathrm{M} ; \mathrm{NaBH}_{4}=1 \mathrm{M} ;$ Au-NPs $=1 \times 10^{-3} \mathrm{~g}$; temperature $10-50{ }^{\circ} \mathrm{C}$ )

Table 1 Reduction rate of $o$-NA at different reaction temperatures

\begin{tabular}{lc}
\hline$T\left({ }^{\circ} \mathrm{C}\right)$ & $K_{\text {app }} \times 10^{-2} \mathrm{~min}^{-1}$ \\
\hline 10 & $3.52 \pm 0.36$ \\
20 & $6.58 \pm 0.65$ \\
30 & $12.93 \pm 0.94$ \\
40 & $21.73 \pm 0.92$ \\
50 & $35.38 \pm 1.07$
\end{tabular}

Reaction conditions $o$-NA $=0.5 \times 10^{-3} \mathrm{M} ; \mathrm{NaBH}_{4}=1 \mathrm{M} ; \mathrm{Au}$ $\mathrm{NPs}=1 \times 10^{-3} \mathrm{~g}$

Recovered NPs were again tested for its catalytic activity for the same reaction. To demonstrate easy recovery of the NPs from the reaction, volume of reagents and catalysts was increased by ten times. Slight change observed in $k_{\text {app }}$ of the recycled catalysts up to five cycles (Table 2). $k_{\text {app }}$ obtained at the fifth cycle was found to be $11.39 \times 10^{-2}$ $\mathrm{min}^{-1}$, suggested catalytic ability of D. regia-mediated Au-

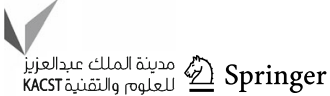


Table 2 Recyclability of biofabricated Au-NPs as catalyst for five cycles

\begin{tabular}{ll}
\hline Cycle & $k_{\text {app }} \times 10^{-2}\left(\mathrm{~min}^{-1}\right)$ \\
\hline 1 & 12.28 \\
2 & 12.19 \\
3 & 11.94 \\
4 & 11.56 \\
5 & 11.39 \\
\hline
\end{tabular}

Reaction conditions $o$-NA $=0.5 \times 10^{-3} \mathrm{M} ; \mathrm{NaBH}_{4}=1 \mathrm{M} ; \mathrm{Au}-$ $\mathrm{NPs}=1 \times 10^{-3} \mathrm{~g}$; temperature $28 \pm 2{ }^{\circ} \mathrm{C}$

NPs remained at about $92 \%$ even after recycling for five consecutive cycles. The slight decrease in catalytic activity of NPs suggested agglomeration of NPs (Kuroda et al. 2009; Koga and Kitaoka 2011) or not fully recovered during recycling process. Thus, biofabricated Au-NPs proved as a potent recyclable catalyst for industrial applications.

\section{Conclusions}

Phyto-synthesis of Au-NPs has been carried out using metal-reducing potential of aqueous $D$. regia leaf extract. Process variables, such as leaf extract concentration, incubation temperature, time, and $\mathrm{pH}$, are important key factors in controlling the SPR, size, and stability of NPs. Spectroscopic (UV-visible and FTIR), structural (XRD), and morphological (TEM) analysis suggest the key role of polyphenolic compounds of $D$. regia in the rapid fabrication of crystalline, pure phase, and spherical Au-NPs of 4-24 nm size through the electrostatic interaction of hydroxyl and carbonyl groups. UV-visible spectroscopy results suggested that biofabricated Au-NPs are a promising candidate for catalytic applications. Therefore, the described strategy for the fabrication of Au-NPs is straightforward, eco-friendly, cost-efficient, and shows a significant great catalytic potential.

Acknowledgments Technical support from the Sophisticated Analytical Instrument Facility (SAIF) and Department of Metallurgical Engineering and Materials Science, Indian Institute of Technology, is gratefully acknowledged. Authors are thankful to Electrical Research and Development Association (ERDA), Vadodara, India, for providing EDX facility for sample characterization.

\section{Compliance with ethical standards}

Conflict of interest There is no conflict of interest.

Open Access This article is distributed under the terms of the Creative Commons Attribution 4.0 International License (http:// creativecommons.org/licenses/by/4.0/), which permits unrestricted use, distribution, and reproduction in any medium, provided you give appropriate credit to the original author(s) and the source, provide a link to the Creative Commons license, and indicate if changes were made.

\section{References}

Agnihotri M, Joshi S, Kumar AR, Zinjarde S, Kulkarni S (2009) Biosynthesis of gold nanoparticles by the tropical marine yeast Yarrowia lipolytica NCIM 3589. Mater Lett 63:1231-1234

Ahmad N, Sharma S, Alam MK, Singh VN, Shamsi SF, Mehta BR, Fatma A (2010) Rapid synthesis of silver nanoparticles using dried medicinal plant of basil. Colloids Surf B 81:81-86

Alani F, Moo-Young M, Anderson W (2012) Biosynthesis of silver nanoparticles by a new strain of Streptomyces sp. compared with Aspergillus fumigatus. World J Microbiol Biotechnol 28:1081-1086

Bai X, Gao Y, Liu HG, Zheng L (2009) Synthesis of amphiphilic ionic liquids terminated gold nanorods and their superior catalytic activity for the reduction of nitro compounds. J Phys Chem C 113:17730-17736

Dauthal P, Mukhopadhyay M (2012) Prunus domestica fruit extractmediated synthesis of gold nanoparticles and its catalytic activity for 4-nitrophenol reduction. Ind Eng Chem Res 5:13014-13020

Dauthal P, Mukhopadhyay M (2013a) In-vitro free radical scavenging activity of biosynthesized gold and silver nanoparticles using Prunus armeniaca (apricot) fruit extract. J Nanopart Res 15:1366-1376

Dauthal P, Mukhopadhyay M (2013b) Biosynthesis of palladium nanoparticles using Delonix regia leaf extract and its catalytic activity for nitro-aromatics hydrogenation. Ind Eng Chem Res 52:18131-18139

Dauthal P, Mukhopadhyay M (2015a) Biofabrication, characterization, and possible bio-reduction mechanism of platinum nanoparticles mediated by agro-industrial waste and their catalytic activity. J Ind Eng Chem 22:185-191

Dauthal P, Mukhopadhyay M (2015b) Agro-industrial waste-mediated synthesis and characterization of gold and silver nanoparticles and their catalytic activity for 4-nitroaniline hydrogenation. Korean J Chem Eng 32:837-844

Dauthal P, Mukhopadhyay M (2016) AuPd bimetallic nanoparticles: single step biofabrication, structural characterization and catalytic activity. J Ind Eng Chem 35:45-53

Gangula A, Podila R, Ramakrishna M, Karanam L, Janardhana C, Rao AM (2011) Catalytic reduction of 4-nitrophenol using biogenic gold and silver nanoparticles derived from Breynia rhamnoides. Langmuir 27:15268-15274

Gardea-Torresdey JL, Gomez E, Peralta-Videa JR, Parsons JG, Troiani H, Jose-Yacaman M (2003) Alfalfa sprouts: a natural source for the synthesis of silver nanoparticles. Langmuir 19:1357-1361

Hudlikar M, Joglekar S, Dhaygude M, Kodam K (2012) Green synthesis of $\mathrm{TiO}_{2}$ nanoparticles by using aqueous extract of Jatropha curcas L. latex. Mater Lett 75:196-199

Jacob SJP, Finub JS, Narayanan A (2012) Synthesis of silver nanoparticles using Piper longum leaf extracts and its cytotoxic activity against Hep-2 cell line. Colloids Surf B 91:212-214

Koga H, Kitaoka T (2011) One-step synthesis of gold nanocatalysts on a microstructured paper matrix for the reduction of 4-nitrophenol. Chem Eng J 168:420-425

Kuroda K, Ishida T, Haruta M (2009) Reduction of 4-nitrophenol to 4-aminophenol over $\mathrm{Au}$ nanoparticles deposited on PMMA. J Mol Catal A: Chem 298:7-11

Liu W, Yang X, Xie L (2007) Size-controlled gold nanocolloids on polymer microsphere-stabilizer via interaction between functional groups and gold nanocolloids. J Colloid Interface Sci 313:494-502 
Metuku RP, Pabba S, Burra S, Bindu NSVSSSLH, Gudikandula K, Charya MAS (2014) Biosynthesis of silver nanoparticles from Schizophyllum radiatum HE 863742.1 their characterization and antimicrobial activity. 3 Biotech 4:227-234

Murugadoss A, Chattopadhyay A (2008) Surface area controlled differential catalytic activities of one-dimensional chain-like arrays of gold nanoparticles. J Phys Chem C 112:11265-11271

Rajathi FAA, Parthiban C, Kumar VG, Anantharaman P (2012) Biosynthesis of antibacterial gold nanoparticles using brown alga, Stoechospermum marginatum (kützing). Spectrochim Acta A Mol Biomol Spectrosc 99:166-173

Sathiya CK, Akilandeswari S (2014) Fabrication and characterization of silver nanoparticles using Delonix elata leaf broth. Spectrochim Acta A Mol Biomol Spectrosc 128:337-341

Sharma NC, Sahi SV, Nath S, Parsons JG, Gardea-Torresde JL, Pal T (2007) Synthesis of plant-mediated gold nanoparticles and catalytic role of biomatrix-embedded nanomaterials. Environ Sci Technol 41:5137-5142

Singh P, Kim YJ, Wang C, Mathiyalagan R, Yang DC (2015) The development of a green approach for the biosynthesis of silver and gold nanoparticles by using Panax ginseng root extract, and their biological applications biological applications. Artif Cells Nanomed Biotechnol 14:1-8

Slocik JM, Naik RR, Stone MO, Wright DW (2005) Viral templates for gold nanoparticle synthesis. J Mater Chem 15:749-753

Srivastava N, Mukhopadhyay $\mathrm{M}$ (2014) Biosynthesis of $\mathrm{SnO}_{2}$ nanoparticles using bacterium Erwinia herbicola and their photocatalytic activity for degradation of dyes. Ind Eng Chem Res 53:13971-13979
Suresh AK, Pelletier DA, Wang W, Broich ML, Moon JW, Gu B, Allison DP, Joy DC, Phelps TJ, Doktycz MJ (2011) Biofabrication of discrete spherical gold nanoparticles using the metalreducing bacterium Shewanella oneidensis. Acta Biomater 7:2148-2152

Tripathy A, Raichur AM, Chandrasekaran N, Prathna TC, Mukherjee A (2010) Process variables in biomimetic synthesis of silver nanoparticles by aqueous extract of Azadirachta indica (Neem) leaves. J Nanopart Res 12:237-246

Wang C, Kim YJ, Singh P, Mathiyalagan R, Jin Y, Yang DC (2015) Green synthesis of silver nanoparticles by Bacillus methylotrophicus, and their antimicrobial activity. Artif Cells Nanomed Biotechnol 6:1-6

Yoosaf K, Ipe BI, Suresh CH, Thomas KG (2007) In situ synthesis of metal nanoparticles and selective naked-eye detection of lead ions from aqueous media. J Phys Chem C 111:12839-12847

Zayed MF, Eisa WH (2014) Phoenix dactylifera L. leaf extract phytosynthesized gold nanoparticles; controlled synthesis and catalytic activity. Spectrochim Acta A Mol Biomol Spectrosc 121:238-244

Zayed MF, Eisa WH, Abdel-Moneam YK, El-kousy SM, Atia A (2015) Ziziphus spina-christi based bio-synthesis of Ag nanoparticles. J Ind Eng Chem 23:50-56

Zhou M, Wang B, Rozynek Z, Xie Z, Fossum JO, Yu X, Raaen S (2009) Minute synthesis of extremely stable gold nanoparticles. Nanotechnology 20:505606 